\title{
FIBROEPITHELIAL POLYP OF THE URETHRA
}

\author{
GIULIANO A. AITA, HELIO BEGLIOMINI, DEMERVAL MATTOS JR
}

\author{
Hospital do Servidor Publico Estadual de Sao Paulo, Sao Paulo, SP, Brazil
}

\begin{abstract}
The fibroepithelial polyp of the urethra is rare in adults. Hematuria and obstructive urinary symptoms are the most common findings. The treatment of choice is endoscopic resection and the prognosis for these lesions is excellent. There is no previous report on recurrence. We describe 2 new cases, with 1 of them presenting recurrence following surgical resection.
\end{abstract}

Key words: urethra; neoplasms, fibroepithelial; polyp

Int Braz J Urol. 2005; 31: 155-6

\section{INTRODUCTION}

Fibroepithelial polyps of the urethra are rare lesions in adults and are most frequently seen in males during the first decade of life. Few cases have been described in the literature so far. As well as physical examination, the investigation for these polyps usually includes imaging exams (voiding cystourethrography and ultrasonography) and urinary endoscopy. However, the diagnosis is primarily established by pathology. There is no association with malignant degeneration.

\section{CASE REPORTS}

\section{Case 1}

A 62-year old male patient reported painless total hematuria for 5 days. He had a previous history of smoking and arterial hypertension. Physical examination and ultrasonography of the urinary tract did not reveal any significant changes. The cystourethroscopy showed a vegetating pediculate lesion measuring approximately $0.5 \mathrm{~cm}$ in diameter located distally from the verumontanum. A transurethral resection was performed and the pathological diagnosis was of a fibroepithelial polyp of the urethra. The patient is asymptomatic after a 1-year follow-up.

\section{Case 2}

A 49-year old female patient presented a history of dysuria and urethral tumor for approximately 4 months. The physical examination showed a polypoid lesion measuring approximately $4 \mathrm{~cm}$ at its longer length originating from the distal third of the urethra and exteriorizing through the external urethral meatus (Figure-1). A cystoscopy was performed, which showed no alteration. The patient underwent exeresis of the lesion using an open approach with a good outcome. The histopathological analysis showed it to be a fibroepithelial polyp of the urethra. The postoperative outcome was good, but 1 year after surgery a new lesion was observed in the same urethral topography with very similar characteristics to the first one. A new exeresis was performed following an analysis of the potential for polypoid reactions, such as inflammatory process and urethral caruncle, because of the patient's age and gender. Potential for these reactions was excluded. 


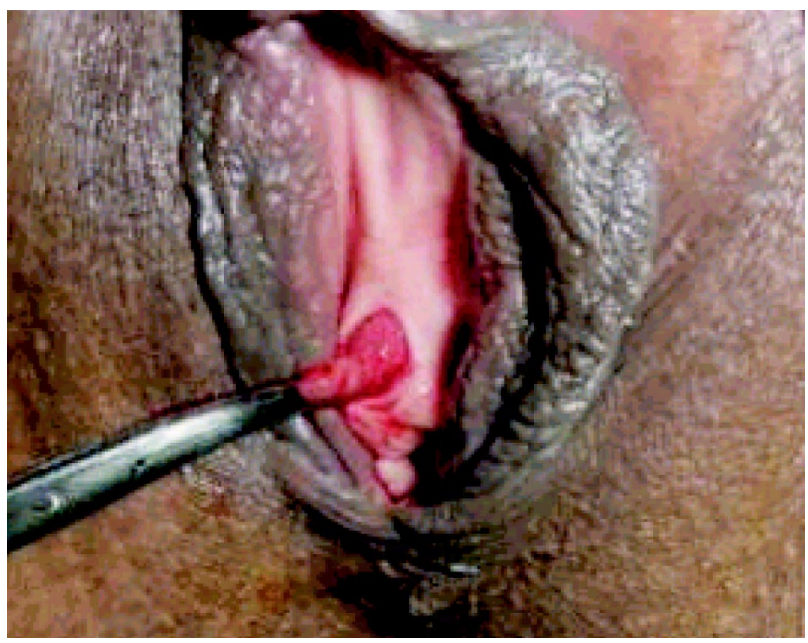

Figure 1 - Fibroepithelial polyp of the urethra exteriorizing through the external urethral meatus.

\section{COMMENTS}

Fibroepithelial polyps of the urethra are usually diagnosed during the first decade of life. They are constituted by connective tissue and smooth muscle cells covered by a normal transitional epithelium or by areas of squamous metaplasia (1).

The most frequent clinical manifestation in adults is hematuria, while obstructive symptoms are predominant in children. A voiding cystourethrography can aid in the diagnosis as it can identify a filling defect at the level of the prostatic urethra in males. Ultrasonography is another addi- tional resource for revealing polypoid lesions that can extend to the bladder neck, and cystourethroscopy allows the direct visualization of the lesion (2). However, diagnosis is primarily confirmed by the lesion's histological analysis. Differential diagnosis includes formations resulting from urothelial reactions, such as inflammatory processes and, in post-menopausal women, urethral caruncles. All these conditions reveal the development of "polypoid" lesions without the characteristics of connective stroma with smooth muscle fibers, which are present in fibroepithelial polyps.

The treatment of choice for urethral polyps is endoscopic resection. The open approach was chosen for this female patient due to the proximity of the lesion to the external urethral meatus. There was also a recurrence of the lesion, something that had not previously been described for fibroepithelial polyps of the urethra. The prognosis of such lesions is excellent and there is no malignant degeneration (3).

\section{REFERENCES}

1. Foster RS, Garret RA: Congenital posterior urethral polyps. J Urol. 1986; 136: 670-2.

2. Lanzas Prieto JM, Menendez Fernandez CL, Perez Garcia FJ, Gutierrez Garcia R, Gonzalez Tuero J, Guate Ortiz JL: Fibroepithelial polyp of the urethra in an adult. Actas Urol Esp. 2003; 27: 654-6.

3. Miroglu C, Ilhan A, Ozdiler E: Congenital urethral polyp in an adult. Br J Urol. 1988; 61: 531-2.

Received: October 10, 2004 Accepted after revision: December 14, 2004

\author{
Correspondence address: \\ Dr. Giuliano Amorim Aita \\ Av. Bem-te-vi, 362 / 91 A \\ Sao Paulo, SP, 045234-030, Brazil \\ E-mail: giulianoaita@hotmail.com
}

